\title{
Individual Variation and Lateral Asymmetry of the Rat Primary Somatosensory Cortex
}

\author{
David R. Riddle and Dale Purves \\ Department of Neurobiology, Duke University Medical Center, Durham, North Carolina 27710
}

\begin{abstract}
We have evaluated the interindividual variability and lateral symmetry of a major cortical area by comparing the primary somatosensory cortex (S1) of adult rats. Our choice of the rat was dictated by the accuracy with which one can measure S1 and its component representations in the rodent brain; the importance of such measurements lies in understanding the rules that govern the allocation of cortical space and, ultimately, the consequences of differential allocation for behavior. With respect to interindividual differences, the major somatic representations in $\mathbf{S 1}$ are surprisingly variable in size. The area of the whiskerpad representation, for example, ranged from 3.72 to $6.84 \mathrm{~mm}^{2}$ in a sample of 53 rats; other components of $\mathbf{S 1}$ showed comparable differences among animals. With respect to lateral symmetry, the average area of each major representation was similar for the right and left hemispheres; thus, we found no consistent bias in the size of $\mathbf{S 1}$ or its elements in the sample as a whole. Within individual animals, however, the sizes of the major somatic representations were often quite different in the two hemispheres. The magnitude of the lateral differences averaged $7.9 \pm 0.8 \%$ (mean \pm SEM) for the whisker pad representation, $11.6 \pm 1.3 \%$ for the upper lip, $15.4 \pm 1.6 \%$ for the furry buccal pad, 13.9 $\pm 1.4 \%$ for the lower jaw, and $13.3 \pm 1.2 \%$ for the forepaw. These results show that the amount of cortical space allocated to corresponding functions in individual rats-or in the two hemispheres of a particular rat-are often different. Such variations are likely to be reflected in somatosensory performance.
\end{abstract}

[Key words: barrels, S1, cerebral asymmetry, cerebral cortex, primary somatic sensory cortex, rat]

The overall size of the brain varies among individuals of a species. The weight of the normal human brain, for example, ranges over several hundred grams (Donaldson, 1895; Le Gros Clark, 1959; Altman and Dittmer, 1962; Cobb, 1965; Dekaban and Sadowsky, 1978). Even the brain weight of an inbred laboratory animal like the rat shows much variability (e.g., Fig. 1 in Riddle et al., 1992). Moreover, the two hemispheres of individual brains are not identical in size or organization (Corballis, 1991; Hellige, 1993; Bradshaw and Rugers, 1993; Iaccino, 1993; Springer and Deutsch, 1993). Understanding the behavioral implications of

\footnotetext{
Received Aug. 31, 1994; revised Dec. 30, 1994; accepted Jan. 19, 1995.

We thank Ann Richards and Marybeth Groelle for excellent technical assistance. This work was supported by NIH Research Grant NS29187.

Correspondence should be addressed to David R. Riddle, Department of Neurobiology, Duke University Medical Center, Box 3209, Durham, NC 27710

Copyright 1995 Society for Neuroscience $0270-6474 / 95 / 154184-12 \$ 05.00 / 0$
}

these differences among individuals - or between the hemispheres-has had a long and troubled history, particularly with respect to the controversial relationship of brain size and "intelligence" (reviewed in Gould, 1981; sec also Purves ct al., 1994). This dilemma notwithstanding, some progress has been made in rationalizing the neurological substrate of particular behaviors. For example, lateralized functions such as human language and handedness have been associated with right/left asymmetries in regions of the hemispheres germane to these behaviors (see, for example, Geschwind and Levitsky, 1968; Wada et al., 1975; White et al, 1994). Because of the difficulties involved in human studies, it would be useful to elucidate the allocation of neural space in an accessible animal model in which functionally distinct regions of the cerebral cortex are more precisely delineated, and in which developmental studies are feasible.

In both these regards, the rodent somatic sensory cortex (S1) is particularly attractive. In the rat and mouse, S1 and its component parts can be recognized and measured using barrels and barrel-like structures as markers to define the primary somatotopic map. Moreover, in the 25 years since barrels were first described by Woolsey and Van der Loos (1970), the rodent S1 and its modular substructure has been studied extensively by researchers interested in how somatic sensory receptors are represented in the cortex (see, for example, Welker, 1971; Welker, 1976, Chapin and Lin, 1984), and how cytoarchitectonic units develop (reviewed in Killackey et al., 1990; Woolsey, 1990). While much has been learned about differences in barrel size and organization among species (see, for example, Woolsey et al., 1975; Rice et al., 1985; Van der Loos et al., 1986; Welker and Van der Loos, 1986; Weller, 1993), relatively little attention has been paid to intraspecies variability, or to the lateral symmetry of this cortical region. Indeed, measured differences in the size of whiskerpad barrels and the posteromedial barrel subfield among small samples of individual animals (or between the two hemispheres) have generally been attributed to technical problems and dismissed (see Discussion). Because of the importance of understanding the relationship between cortical space and behavior, we have undertaken a detailed study of the normal variation of the dimensions of $S 1$ in a large sample of rats. Our results show that rodents differ in the amount of cortical space allocated to corresponding functions, both among individuals and between the two hemispheres of a given animal.

\section{Materials and Methods}

A total of 53 adult male rats (approximately 15 weeks old, SpragueDawley strain) were examined. The animals were purchased from Harlan Sprague-Dawley, Indianapolis, IN, or Charles River, Raleigh, NC; the rats from one supplier did not differ significantly from those of the 

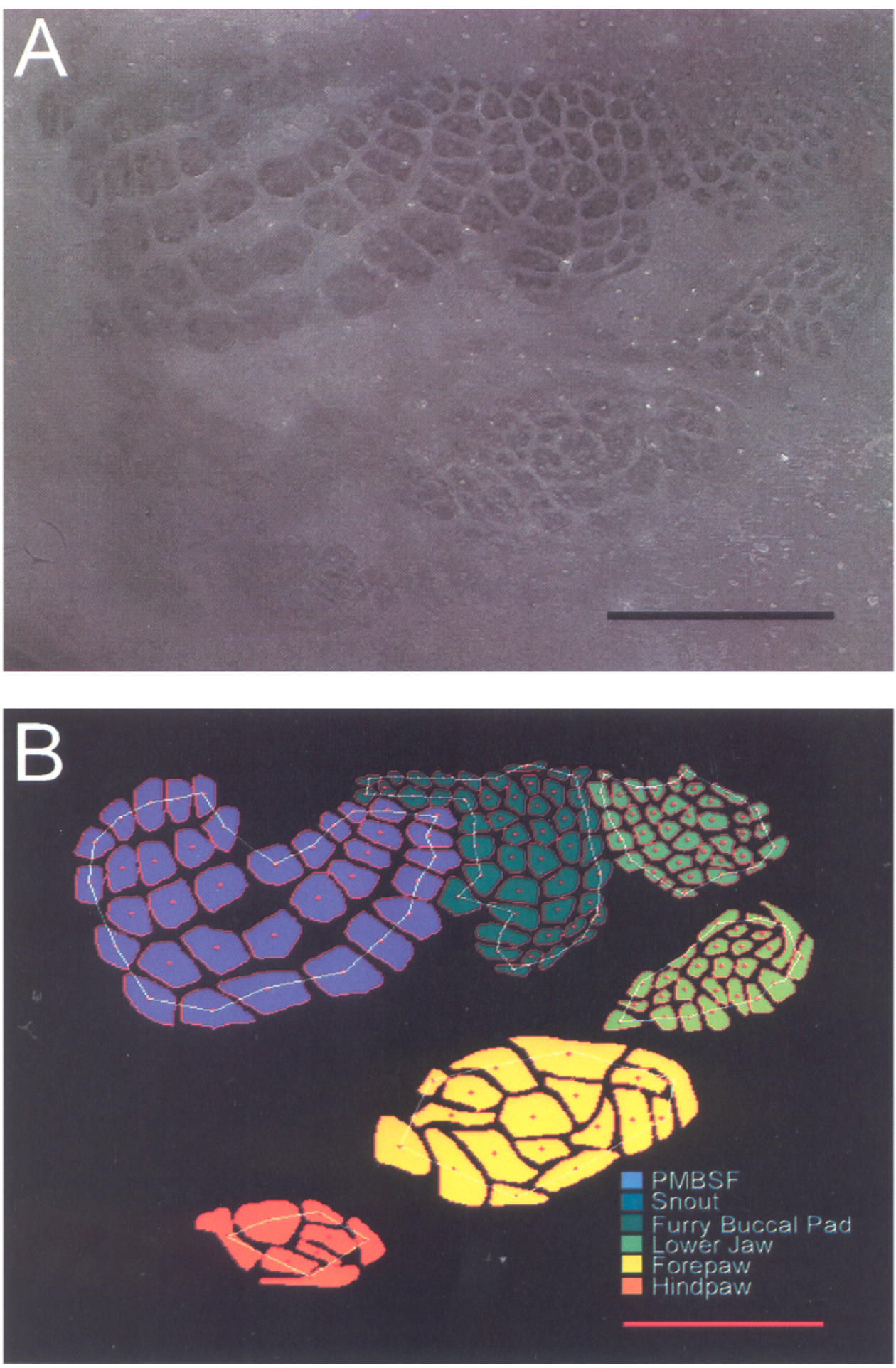

Figure 1. Histochemical demonstration of primary somatosensory cortex in the rat, and definition of its component parts. $A$, Digitized image of a single SDH-stained tangential section of the primary somatosensory cortex of an adult ( 15 week old) rat. $B$, Complete S1 map in the same animal, reconstructed from eight sections. The barrels are shown in gray; the interbarrel areas (yellow) and the total area of each somatic representation were defined using the centroids of the outermost barrels in each representations as in Riddle et al., 1992. Patterns of mitochondrial enzyme staining are known to match the cytoarchitecture definition of barrels quite precisely in the rat (see, e.g., Fig. 7 in Riddle et al., 1992). Scale bar, $2 \mathrm{~mm}$. other for any measure of S1. Each animal was deeply anesthetized with sodium pentobarbital $(250 \mathrm{mg} / \mathrm{kg}$, i.p.) and perfused through the heart with saline followed by $10 \%$ glycerol. The brain was quickly removed and the cortical mantles dissected free from the underlying structures. To incorporate the entire S1 map in as small a number of sections as possible (as well as to minimize variation arising from sectioning S1 at different angles), the mantles from each brain were carefully flattened after placing them side by side between Teflon-coated glass slides held exactly $2 \mathrm{~mm}$ apart by spacers. While still compressed, the flattened cortices were rapidly frozen in 2 -methylbutane cooled to $-40^{\circ} \mathrm{C}$. Serial tangential sections were cut in a cryostat at $50 \mu \mathrm{m}$ and thaw mounted on glass slides; the sections from both hemispheres of each brain were stained together for succinate dehydrogenase (Nachlas et al., 1957; reaction time $=45 \mathrm{~min}$ ), the method that best reveals the barrels and barrel-like structures that delineate $\mathrm{S} 1$ and its component parts (Fig. 1A; Killackey and Belford, 1979; Dawson and Killackey, 1987; Wallace, 1987; Riddle et al., 1992). Two-dimensional maps of the flattened somatosensory cortex were traced from the tangential sections at a final magnification of $28 \times$ using a camera lucida. The border of each barrel was traced from the section in which it was most sharply defined. An average of $8.1 \pm 1.3(\mathrm{SD})$ sections were compiled for each complete map of $\mathrm{S} 1$; radial blood vessels and barrels were used to align sequential sections. The fact that, on average, eight sections were compiled indicates that the cortex cannot be perfectly flattened. The average thickness 
Table 1. Average percentage differences between two independent measurements of the major somatic representations in S1 from 12 hemispheres $(N=8$ rats $)$

Percentage differences

\begin{tabular}{|c|c|c|c|c|c|c|}
\hline & \\
\hline & PMBSF & Lip & $\begin{array}{l}\text { Furry } \\
\text { buccal pad }\end{array}$ & $\begin{array}{l}\text { Lower } \\
\text { jaw }\end{array}$ & Forepaw & $\begin{array}{l}\text { Combined } \\
\text { representations }\end{array}$ \\
\hline Total barrel area & $1.4 \pm 0.4$ & $3.7 \pm 0.6$ & $7.1 \pm 1.1$ & $7.0 \pm 1.1$ & $5.4 \pm 1.0$ & $1.6 \pm 0.2$ \\
\hline Overall area & $1.0 \pm 0.1$ & $3.0 \pm 0.5$ & $5.0 \pm 1.1$ & $4.6 \pm 1.1$ & $3.7 \pm 0.5$ & $0.9 \pm 0.1$ \\
\hline
\end{tabular}

Each value is the magnitude (mean \pm SEM) of the difference calculated according to the formula $|(1 \mathrm{st}-2 \mathrm{nd}) /[(1 \mathrm{st}+2 \mathrm{nd}) / 2]| \times 100$.

of barrels in the radial dimension is approximately $270 \mu \mathrm{m}$ in adult rats (Riddle et al., 1992); thus, only six to seven sections would need to be compiled if the entire map were compressed into exactly the same plane. Completed maps were digitized at a resolution of $512 \times 480$ using a HP2C flat-bed scanner (Hewlett Packard, Corvallis, OR); image processing and analysis were carried out with IMAGE 1/AT software (Universal Imaging, West Chester,

Measurements and definitions. The primary somatosensory cortex of the rat comprises approximately $200 \mathrm{SDH}$-rich barrels and barrel-like structures (see Fig. 1A). For convenience, we refer to these elements simply as barrels. Most of the barrels are grouped into six discrete somatic representations: the whisker pad (also called the posteromedial barrel subfield or PMBSF; Woolsey and Van der Loos, 1970), the upper lip, the furry buccal pad, the lower jaw, the forepaw, and the hindpaw (Fig. $1 B$ ). The hindpaw region was not included in this study because of its relatively poor definition in some adult animals (see Riddle et al., 1993). For every hemisphere we calculated the total barrel area in each representation (i.e., the sum of the areas of the individual barrels), as well as the overall area of the representation (i.e., the sum of the barrel and interbarrel areas). This latter determination was made using the borders and centroids of the outermost barrels to define each representation (see Fig. $1 B$ and Riddle et al., 1992). Individual variation in the size of S1 and its component parts was assessed by the range of measured areas in the 53 animals we examined. Hemispheric variationthat is, lateral asymmetry - was assessed by (1) testing for a population bias, (2) examining lateral asymmetry in individual rats, and (3) testing the correlation of the asymmetries observed among the five representations in each of the 53 animals studied. To test for a population bias, we compared the average area of each region in the left hemispheres of the 53 rats to the average area in the right hemispheres. To evaluate lateral asymmetry within individuals, we plotted the area of each region in the left hemisphere against the area of the corresponding region in the right hemisphere; we also determined the percentage difference between the areas of the corresponding regions in right and left hemispheres, calculated as (right - left $) /\{$ (right + left) $/ 2\} \times 100$. Using the percentage difference facilitated comparison among different animals (and representations), since this parameter normalizes differences in brain size (and differences in the size of the various representations within S1). Finally, to evaluate whether regional asymmetries were similar for the major representations in a given animal, we determined the degree of correlation of the asymmetries (measured as percentage differences) in the five somatic representations by calculating correlation coefficients.

Estimation of experimental error. The ability to reliably mcasurc interindividual and lateral differences in the size of $S 1$ and its components depends upon the consistency of several methodological factors, including tissue processing, sectioning angle, recognition of barrels, and tracing of barrel borders. Differences in the degree of flattening (or in the angle of sectioning) would artificially increase variability and apparent lateral differences (see Woolsey and Van der Loos, 1970; Welker and Woolsey, 1974). To address this issue, we evaluated whether the measured sizes of the representations in S1 were related to the number of sections required to make a complete map (an indication of the degree of flattening and angle of section; see above). The size of the S1 representations was not related to the number of sections compiled (eight on average; see above) for each completed map $(r=-0.17, p$
$>0.05$ by Spearman rank correlation). We also determined whether, in each animal, the measured asymmetries between the hemispheres were similar for each of the representations in S1. They were not (see Results). One would expect all regions of $\mathrm{S} 1$ to be similarly affected by differences in flattening or angle of section. Finally, to test our ability to reproducibly identify, draw, and measure barrels and the major S1 representations, the sections from a subset of 12 hemispheres (from eight rats) were coded, drawn and measured in the usual manner; we then recoded the slides and drew and measured them a second time. The average percentage differences between the first and second measurements for the total barrel area in each representation ranged from $1 \%$ for the PMBSF to $7 \%$ for the smaller representations of the furry buccal pad and lower jaw (Table 1). The variation in the measurements of the overall area of each representation ranged from $1 \%$ for the PMBSF to $5 \%$ for the furry buccal pad and lower jaw.

\section{Results}

\section{Individual variation of $S 1$ and its components}

Brain weights of the 53 rats used in the study ranged from 1537 to $2079 \mathrm{mg}$ (mean $\pm \mathrm{SD}=1799 \pm 19$ ). The combined area of the five major representations in $\mathrm{S} 1$ in 106 hemispheres (53 animals) ranged from 9.37 to $16.30 \mathrm{~mm}^{2}$. Measures of the individual representations also showed substantial variability, with a greater than twofold range of values (Fig. 2). These differences in the size of $\mathrm{Sl}$ and its component parts were not simply the result of variation in overall brain size. Thus, individual values of brain weight werc not correlated with the area of any of the representations within $\mathrm{S} 1$ ( $r$ values ranged from 0.03 to 0.15 for the five representation), although the area of the combined representations was weakly correlated with brain weight $(r=0.35$, $p<0.05$, Spearman rank correlation), as might be expected. To more fully evaluate the degree to which variability in brain size might account for the differences in the size of S1, we divided the 53 rats into six groups based on brain weight, and reexamined the range of $\mathrm{S} 1$ sizes. The range of brain weights for each group was less than $100 \mathrm{mg}$, and the maximum values were no more than $5 \%$ greater than the minimum values. Nonetheless, we still found much variation in the size of $\mathrm{S} 1$ within each of the six groups: the maximum value within a group for the area of the $\mathrm{S} 1$ representations was, on average, $46 \%$ greater than the minimum value. In short, the area of S1 and its constituent parts varies substantially among normal adult rats, even after taking variations in body and brain size into account.

\section{Hemispheric asymmetry of $S I$ and its components}

Average values for the total barrel area and the overall area of the five major representations in the right hemisphere of the 53 rats examined were not significantly different from the average

Figure 2. Interindividual variability in the size of S1. The distribution of barrel areas (left column) and overall areas (right column) for the five representations and the five combined are shown for the left (open bars and symbols) and right (hatched bars and solid symbols) hemispheres from 53 rats. The number of animals is indicated on the ordinate. Diamonds indicate mean values for the 53 animals; triangles mark \pm 1 SD. 
Barrel Area $\left(\mathrm{mm}^{2}\right)$
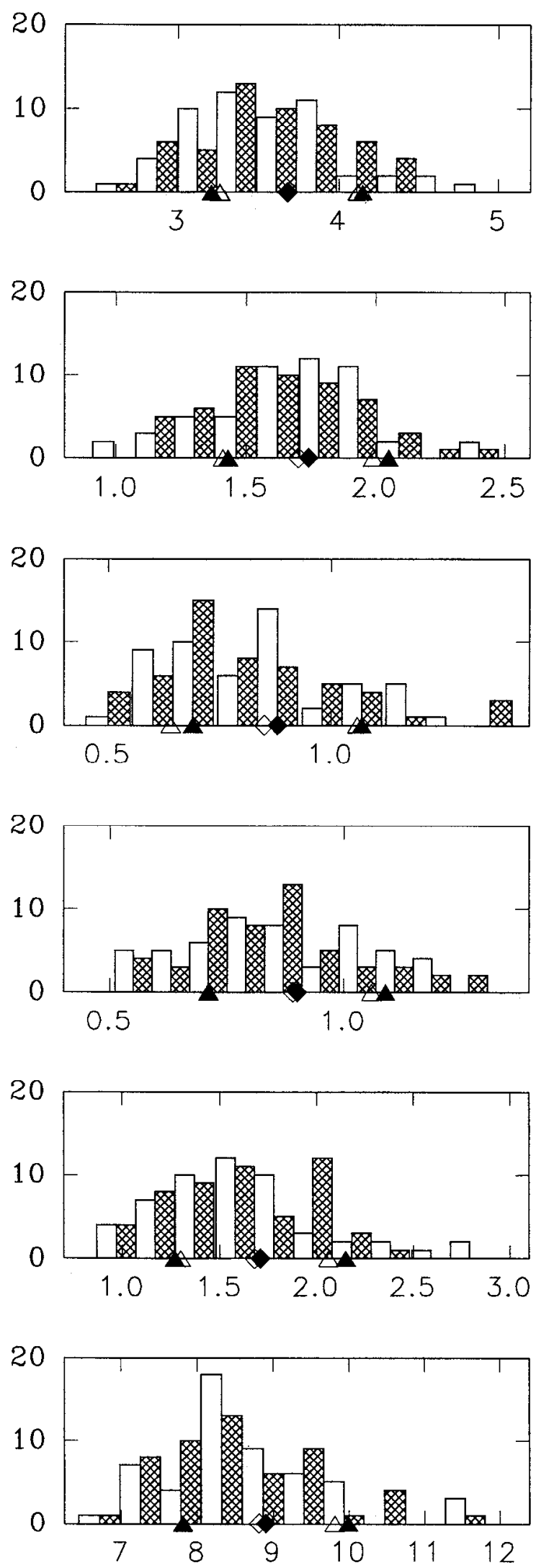

Overall Area $\left(\mathrm{mm}^{2}\right)$
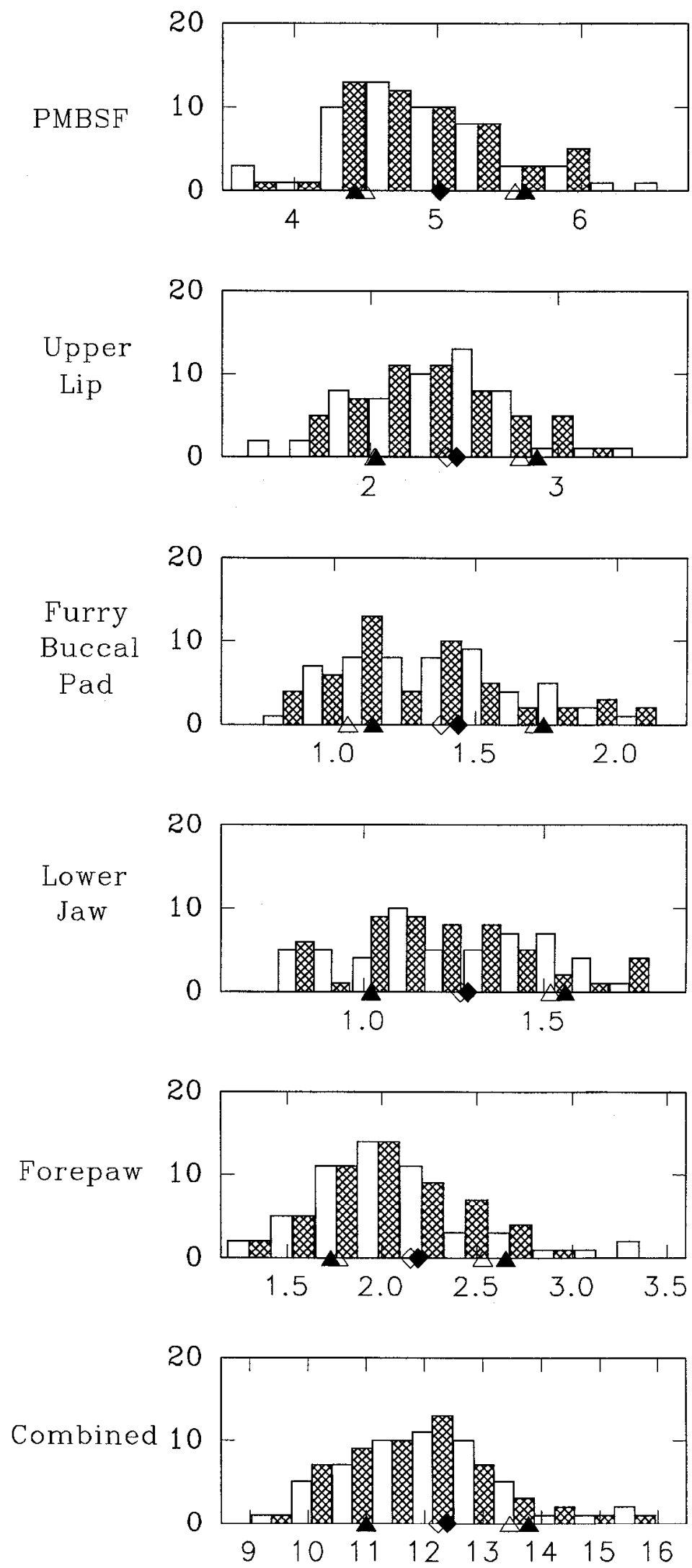
Table 2. Lateral symmetry in the experimental population of 53 adult male rats

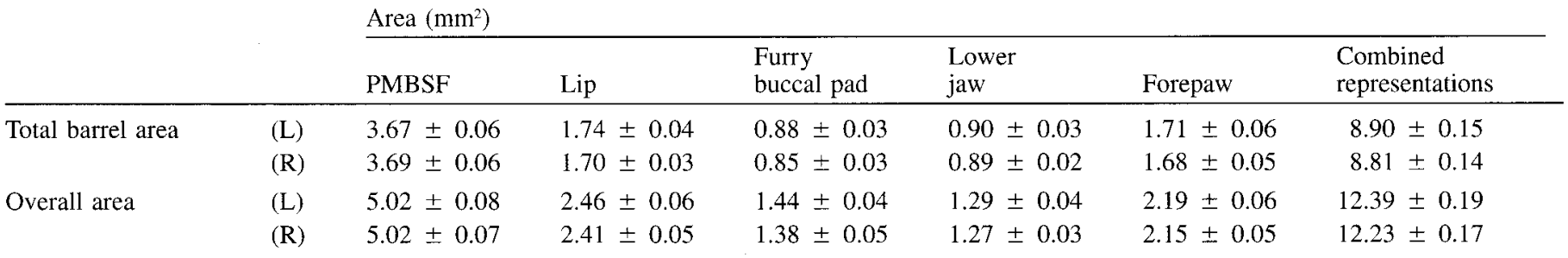

The mean $( \pm$ SEM) barrel area and overall area of the major somatic representations are given for the left $(L)$ and right (R) hemispheres of 53 rats. No significant differences were observed between the left and right values for any measure of $S 1$ (all $p$ values $>0.15$ by paired $t$ tests).

values in the left hemisphere (Table $2 ; p$ values determined by paired $t$ tests ranged from 0.15 to 0.95 ). Thus, we found no evidence of a directional bias in the size of SI or its component parts in the sample as a whole, a finding consistent with previous reports of average lateral symmetry of the barrel subfield in populations of mice and rats (Jeanmonod et al., 1981; Tobet et al., 1993).

Despite the overall symmetry of S1 in the sample as a whole, individual animals showed clear lateral differences in the size of S1 and its elements (Figs. 3-7). The asymmetry observed was typically much greater than the variability of repeated measurements of the same hemisphere (see Table 1). Thus, the total barrel area in each of the five major somatic representations could differ by $20 \%$ or more (Fig. 5). The average magnitude of these right-left differences (Table 3 ) ranged from $8 \%$ for the PMBSF to $17 \%$ for the furry buccal pad. The average magnitude of the $Z$ score for the differences between the right and left hemispheres (which also normalizes for the size of the representation) was 0.81 for the PMBSF, 0.72 for the lip, 0.78 for the furry buccal pad, 0.79 for the jaw, and 0.79 for the forepaw. In general, there appeared to be somewhat less asymmetry of the combined representations than of the individual representations (Table 3). Finally, approximately equal numbers of animals (and representations) were biased to the left as to the right (see Fig. 5).

Lateral differences were equally apparent in the overall area of the five representations within S1 (i.e., the area determined by including both barrel and interbarrel cortex; Fig. 6). The average magnitude of these right-left differences (Table 3) ranged from $8 \%$ for the PMBSF to $15 \%$ for the furry buccal pad. As in the case of the total barrel area, lateral differences in the overall size of the combined representations were somewhat smaller than those of the individual representations (Table 3), and leftward and rightward biases were about equally common (Fig. 7).

\section{Independence of hemispheric asymmetry among the major S1 representations}

Given that each somatic representation is often laterally asymmetrical, we asked whether the same hemisphere was favored for most or all of the representations in a given animal. Qualitative examination of the right-left differences for the individual representations in each animal (Figs. 5,7) suggested this was not the case, as did the observation that the average magnitudes of the right-left differences for the individual representations were greater than that for the combined representations (Table 3 ). Statistical analysis of the 10 possible correlations between the five major representations that we examined in $S 1$ confirmed that the asymmetry of one region was correlated only with that of the adjacent representation, as might be expected simply on the basis of proximity (Table 4). Thus, the lateral asymmetry of a particular representation in an individual animal is independent of the asymmetry of most other representations, indicating that the asymmetries observed are not the result of global hemispheric differences.

\section{Discussion}

The evidence we report here shows that the rat brain, at least as judged by $\mathrm{S} 1$ and its component parts, varies greatly among individuals as well as from hemisphere to hemisphere in the same animal. To our knowledge, no major anatomical study of this sort has been carried out in the primary somatic sensory cortex of any species, despite the general importance of normative brain differences. Although we take it for granted that the range of normal human abilities varies greatly - and that the two hemispheres differ substantially in function-the structural bases for these functional variations are not known (see Purves et al., 1994). In part, this deficit is due to the difficulty of visualizing and accurately measuring functional areas in complex, gyrencephalic brains. In the rat, however, S1 and its elements can be readily defined by several techniques, and measured with considerable accuracy (see Materials and Methods).

Barrels, particularly those of the PMBSF, have been analyzed extensively since Woolsey and Van der Loos first provided a detailed description of these structures in 1970. Several investigators have noted variation of the size of whisker barrels (or of the posteromedial barrel subfield itself) among individual animals, or between the two sides of a given brain. Whether these apparent differences are real or artifactual, however, has never been clearly determined; indeed such variations have generally been ascribed to methodological problems. Woolsey and Van der Loos (1970) reported differences in barrel size between two hemispheres (one hemisphere from each of two mice), but suggested the differences arose from variations in the plane of section. Later, Pasternak and Woolsey (1973) reported that the cross-sectional area of barrel $\mathrm{Cl}$ (and corrected neuronal counts therein) varied among 11 hemispheres from eight mice. They indicated that this variability was partially artifactual, and suggested that the issue be studied further. In the same paper, the authors noted that for two of three animals in which both sides of the brain were examined there appeared to be a better correlation of barrel size (and neuron number) between the two hemispheres of a given animal than among different animals. The third animal, in which the area of the $\mathrm{Cl}$ barrel in the two hemispheres differed by $27 \%$ (see Table 1 in Pasternak and Woolsey, 1973), was not discussed. Welker and Woolsey (1974) reported a range of $2.43-2.82 \mathrm{~mm}^{2}$ for the area of the PMBSF in a sample of four rats, but did not indicate whether they con- 


\section{Left}

A

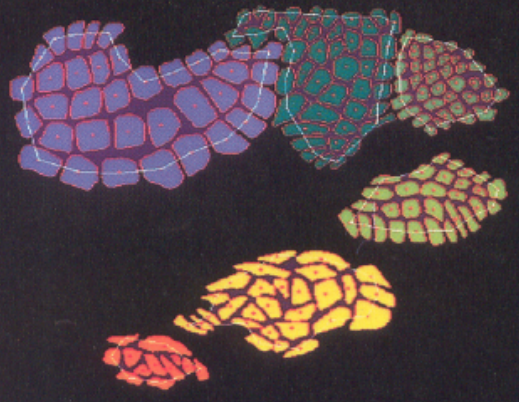

$\mathrm{B}$
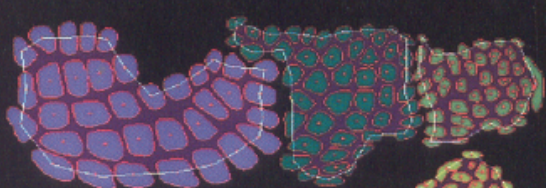
1) 009 $8 \%$ cos sogetor.
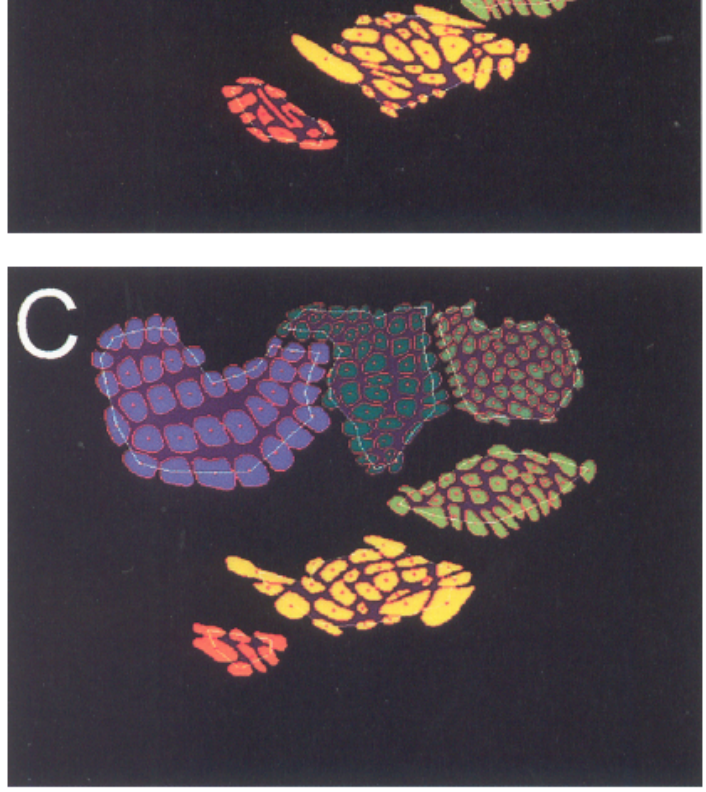

\section{$\mathrm{D}$}

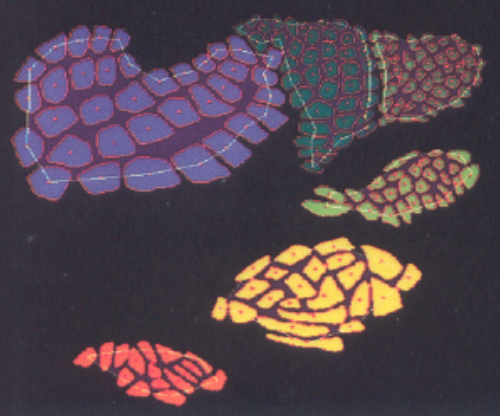

\section{Right}
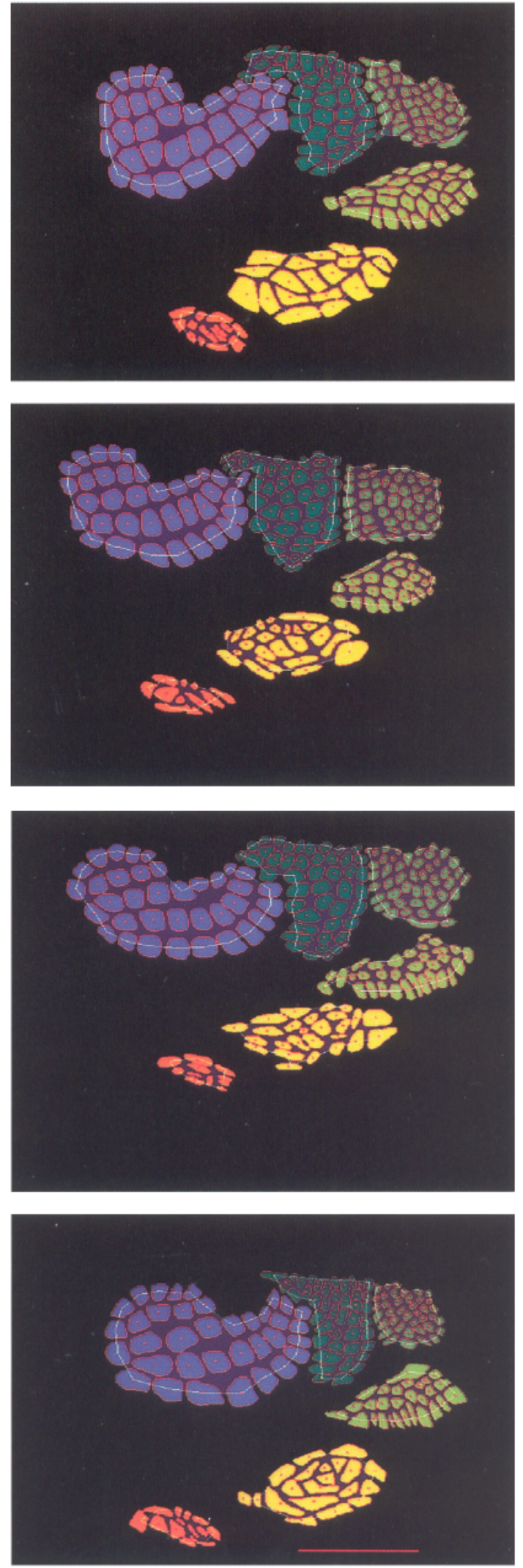

Figure 3. Complete $\mathrm{S} 1$ maps from the left and right hemispheres of four representative rats. 

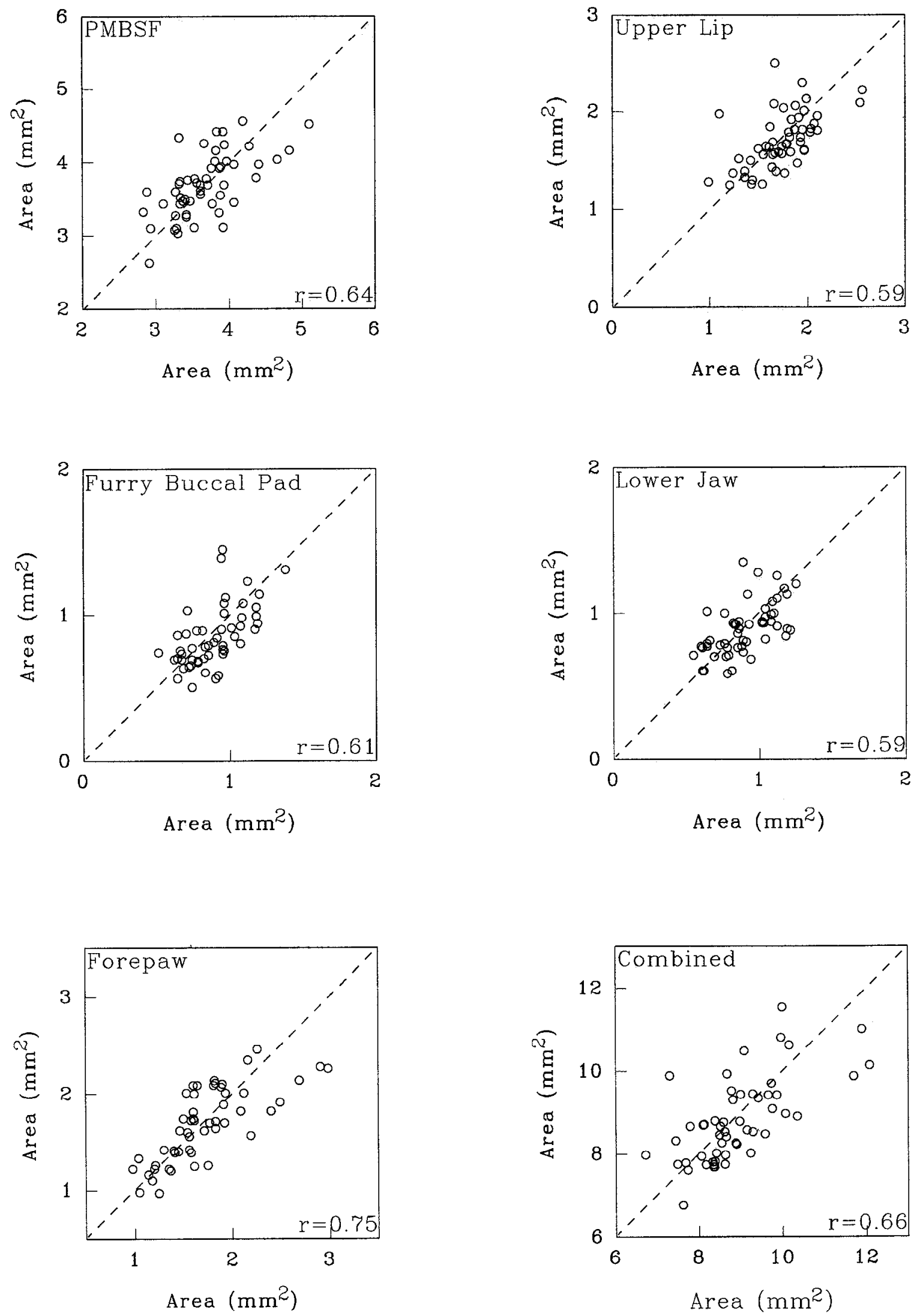

Figure 4. Lateral asymmetry of the barrel area in each representation. The total barrel areas for each of the five representations (and for the combined representations) from the right hemisphere (ahscissa) are plotted against the corresponding values from the left hemisphere (ordinate; $N$ $=53$ animals). The dashed line represents perfect symmetry. 


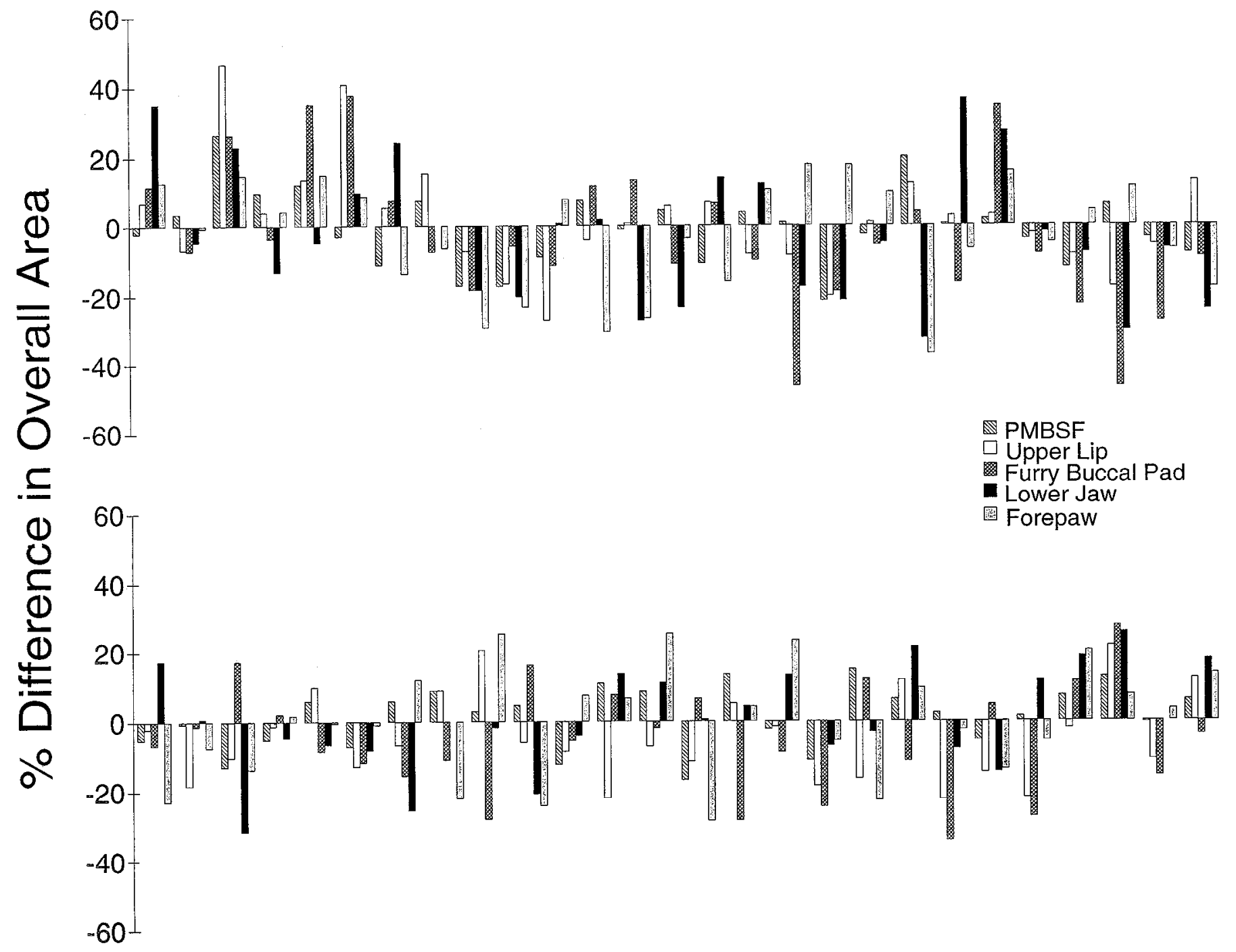

Figure 5. Magnitude and direction of lateral asymmetry of the total barrel area for the major somatic representations in S1. Each set of five bars indicates the percentage difference (right minus left) in the barrel area of the five representations examined in the right and left hemispheres of a particular rat $(N=53$ rats, divided into two plots for clarity). For most rats, the degree and direction of asymmetry varies among the representations (see also lable 2). For the group as a whole, however, there are approximately the same number of animals (and representations) biased to the right as to the left.

sidered this variation to be real or specious. (Note that these values derived from measurements of fixed tissue cannot be compared directly to our own measurements in freshly frozen material). More recently, Welker and Van der Loos (1986) argued that, in contrast to significant differences between strains of mice, there is little variation in barrel size among animals of a given strain (or, presumably, between the two hemispheres of a given mouse). However, their data on the average size of individual barrels in each strain showed standard deviations that were $10-15 \%$ of the mean barrel area (see Fig. 4 in Welker and Van der Loos, 1986). Thus, despite some indications of variability and lateral asymmetry, the impression has been left that the size of barrels and the barrel field are under tight genetic control, and subject to little variation (see Welker and Van der Loos, 1986).

Our analysis of 53 adult rats shows interindividual variability similar to that suggested by these earlier studies. We also found obvious hemispheric asymmetry in the size of $\mathrm{Sl}$ and its component parts. In contrast to previous conclusions, however, our analysis indicates this variability in the size of the $S 1$ and its components cannot be dismissed as artifactual. Several observations indicate that the variability in S1 size we describe is not the result of differential flattening or other differences in tissue processing. We have previously shown that the flattening procedure we used (which minimizes problems related to the angle of section) produces only a small increase in the surface area of the cortex $(6.0 \pm 1.1 \%$ enlargement; see Riddle et al., 1992). The increases in area due to flattening (and the range of increases observed) are too small by at least an order of magnitude to account for the variability in measured areas reported here. Furthermore, we found no correlation between the size of $S 1$ or its components and the number of sections required to compile each map. Perhaps most importantly, the differences in size of the somatic representations within S1 vary in a largely independent manner (see Table 4); it is difficult to imagine how differential flattening or other technical flaws in tissue processing could produce this result. It is equally unlikely that the variability we describe is due to simple measurement error, since the range of 

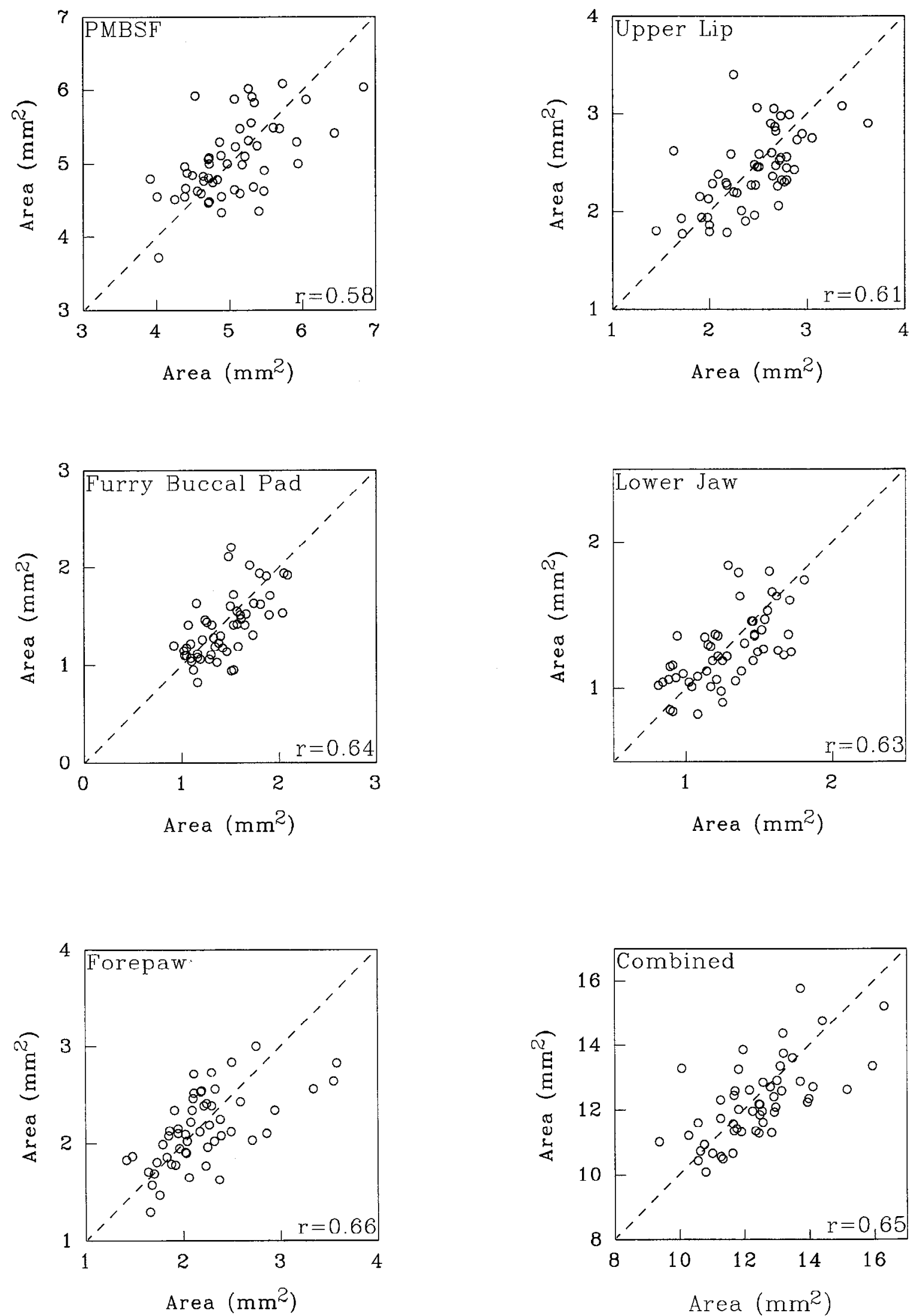

Figure 6. Lateral asymmetry of the overall ared for each representation. The total banel areas for each of the five representations (and for the combined representations) from the right hemisphere (abscissa) are plotted against the corresponding values from the left hemisphere (ordinate, $N$ $=53$ animals). The dashed line represents perfect symmetry. 


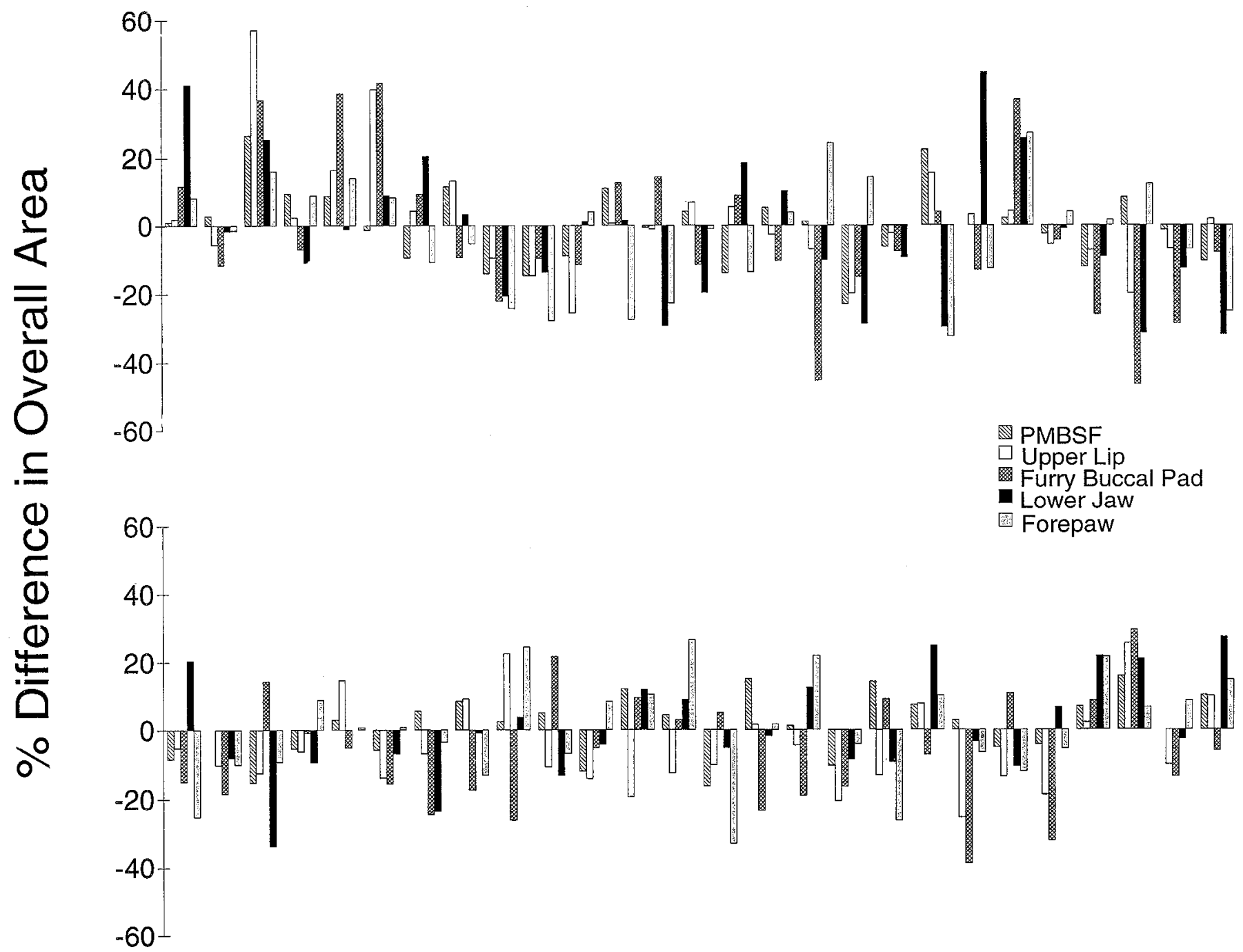

Figure 7. Magnitude and direction of lateral asymmetry for the major somatic representations in S1 (plotted here for the overall area of each representation). Each set of five bars indicates the percentage difference (right minus left) in the size of the five representations in the right and left hemispheres of a single rat $(N=53$ rats, divided into two plots for clarity). For most rats, the degree and direction of asymmetry varies substantially among the representations. Note that there are approximately equal numbers of rightward and leftward biases for the group as a whole.

right-left differences and interindividual variability were much greater than the differences between sequential measurements of the same cortex.

Our conclusion that there are significant interindividual and hemispheric differences in the size of a major cortical region in the rat brain is consistent with studies of this issue in primates. Stensaas et al. (1974) reported a threefold range in the size of V1 in a sample of 52 human brains, and smaller, but sometimes dramatic, interhemispheric differences. Other studies have reported significant interindividual variation in the size of V1 and other visual areas in the brains of other primates (Van Essen et al., 1981, 1984; Krubitzer and Kaas, 1990; Purves and LaMantia, 1993).

The larger importance of these interindividual and hemispheric differences in the size of S1 and its components in mammals is their consequence for behavior. That the amount of neural circuitry associated with a behavior influences performance is perhaps obvious when one considers how the specialized abilities of particular species are realized in brain structure. Comparisons across species show that special behavioral talents are

Table 3. Lateral asymmetry of S1 and its components in individual rats

\begin{tabular}{lllllll}
\multicolumn{2}{l}{} & \multicolumn{2}{l}{ Percentage differences } \\
\cline { 2 - 7 } & PMBSF & Lip & $\begin{array}{l}\text { Furry } \\
\text { Buccal pad }\end{array}$ & $\begin{array}{l}\text { Lower } \\
\text { jaw }\end{array}$ & Forepaw & $\begin{array}{l}\text { Combined } \\
\text { representations }\end{array}$ \\
\hline Total barrel area & $8.2 \pm 0.9$ & $11.8 \pm 1.4$ & $17.0 \pm 1.6$ & $14.4 \pm 1.6$ & $12.9 \pm 1.3$ & $7.6 \pm 0.8$ \\
Overall area & $7.9 \pm 0.8$ & $11.6 \pm 1.3$ & $15.4 \pm 1.6$ & $13.9 \pm 1.4$ & $13.3 \pm 1.2$ & $7.0 \pm 0.7$
\end{tabular}


Table 4. Correlation analysis of the independence of asymmetry in the major somatic representations of $\mathrm{S} 1$

\begin{tabular}{lllll} 
Upper & $\begin{array}{l}\text { Furry } \\
\text { buccal }\end{array}$ & Lower \\
PMBSF & lip & pad & jaw & Forepaw \\
\hline
\end{tabular}

\begin{tabular}{llllll}
\hline PMBSF & - & - & & \\
Upper lip & $0.53^{*}$ & - & & \\
Furry buccal pad & 0.25 & $0.61^{*}$ & - & \\
Lower jaw & 0.26 & $0.38^{*}$ & $0.35^{*}$ & - & \\
Forepaw & 0.22 & 0.14 & 0.09 & $0.32^{*}$ & -
\end{tabular}

$\overline{\text { Each Pearson correlation coefficient indicates the degree of covariance between }}$ the two indicated regions.

* $p$ value $<0.05$

invariably based on commensurately sophisticated brain circuitry, which entails more neurons, more synapses, more supporting glial cells, and therefore the occupancy of more space in the brain. Among the examples that could be cited to make this point are the organization of the auditory cortex in echolocating bats (Suga and Jen, 1976; Suga and O'Neill, 1980; Suga et al., 1981; Suga, 1984), the disproportionately large representation of the hands in the human and raccoon sensorimotor cortex (Penfield and Boldrey, 1937; Penfield and Rasmussen, 1950; Woolsey, 1958; Johnson, 1980), and the large fraction of the somatosensory cortex in the star-nosed mole given over to the representation of the nasal appendages that provide a major source of mechanosensory information to this animal (Catania et al., 1993). Not surprisingly, when a species shows a particularly well developed behavior, a disproportionate fraction of the animal's brain is allocated to that task.

The relationship between behavior and the allocation of neural space suggested by such phylogenetic examples may be equally pertinent to the neural hasis of differential behavior among individual members of a species, or even the functional differences that exist in the two hemispheres of a particular brain. Recent studies have suggested that handedness, a straightforward model of preferred human behavior, is based on the asymmetrical elaboration of neural centers devoted to the representation of the favored limb (White et al., 1994; see also Purves et al., 1994a,b). In subhuman primates, the hand region of the primary motor cortex of squirrel monkeys (determined electrophysiologically) is also larger and more complex in the hemisphere controlling the preferred hand (Nudo et al., 1992). Since behaviors that are preferred or better executed are evidently based on proportionately more circuitry in the related neural centers, the differences in $\mathrm{S} 1$ that we describe here should be reflected in somatosensory performance.

\section{References}

Altman PL, Dittmer DS (1962) Growth, including reproduction and morphological development. Bethesda, MD: Federation of American Societies for Experimental Biology.

Bradshaw B, Rogers L (1993) The evolution of lateral asymmetries, language, tool use, and intellect. San Diego: Academic.

Catania KC, Northcutt RG, Kaas JH, Beck PD (1993) Nose stars and brain stripes. Nature $364: 493$.

Chapin JK, Lin C-S (1984) Mapping the body representation in the SI cortex of anesthetized and awake rats. J Comp Neurol 229:199-213.

Cobb S (1965) Brain size. Arch Neurol 12:555-561.

Corballis MC (1991) The lopsided ape: evolution of the generative mind. New York: Oxford UP.

Dawson DR, Killackey HP (1987) The organization and mutability of the forepaw and hindpaw representations in the somatosensory cortex of neonatal rat. J Comp Neurol 256:246-256.

Dekaban AS, Sadowsky D (1978) Changes in brain weights during the span of human life: relation of brain weight to body heights and body weights. Ann Neurol 4:345-356.

Donaldson $\mathrm{HH}$ (1895) Growth of the brain: study of the nervous system in relation to education. New York: Scribner.

Geschwind N, Levitsky W (1968) Human brain: left-right asymmetries in temporal speech region. Science 161:186-187.

Gould SJ (1981) The mismeasure of man. New York: Norton.

Hellige JB (1993) Hemispheric asymmetry: what's right and what's left. Cambridge, MA: Harvard UP.

Iaccino JF (1993) Left brain-right brain differences: inquiries, evidence and new approaches. Hillsdale, NJ: Erlbaum.

Jeanmonod D, Rice FL, Van der Loos II (1981) Mouse somatosensory cortex: alterations in the barrelfield following receptor injury at different early postnatal ages. Neuroscience 6:1503-1535.

Johnson JI (1980) Morphological correlates of specialized elaborations in somatic sensory cerebral neocortex. In: Comparative neurology of the telencephalon (Ebesson SOE, ed), pp 423-447. New York: Plenum.

Killackey HP, Belford GR (1979) The formation of afferent patterns in the somatic sensory cortex of the neonatal rat. I Comp Neurol 183: 285-304.

Killackey HP, Jacquin MF, Rhoades RW (1990) Development of somatosensory system structures. In: Development of sensory systems in mammals (Coleman JR, ed), pp 403-429. New York: Wiley.

Krubitzer LA, Kaas JH (1990) Cortical connections of MT in four species of primates: areal, modular and retinotopic patterns. Vis Neurosci 5:165-204.

Le Gros Clark WE (1959) The crucial evidence for human evolution. Proc Am Philos Soc 103:159-172.

Nachlas MM, Tsou KC, DeSousa E, Cheng CH, Seligman AM (1957) Cytochemical demonstration of succinic dehydrogenase by the use of a new $p$-nitrophenyl substituted ditetrazole. J Histochem Cytochem 5:420-436.

Nudo RJ, Jenkins WM, Merzenich MM, Prejean T, Grenda R (1992) Neurophysiological correlates of hand preference in primary motor cortex of adult squirrel monkeys. J Neurosci 12:2918-2947.

Pasternak JF, Woolsey TA (1973) The number, size and spatial distribution of neurons in lamina IV of the mouse SmI neocortex. J Comp Neurol 160:291-306.

Pentield W, Boldrey E (1937) Somatic motor and sensory representation in the cerebral cortex of man as studied by electrical stimulation. Brain 60:389-443.

Penfield W, Rasmussen T (1950) Sensorimotor representation of the body. In: The cerebral cortex of man, pp 12-65. New York: MacMillan.

Purves D (1994) Neural activity and the growth of the brain. Cambridge, UK: Cambridge UP.

Purves D, LaMantia A (1993) Development of blobs in the visual cortex of macaques. J Comp Neurol 334:169-175.

Purves D, White LR, Andres TJ (1994a) Manual asymmetry and handedness. Proc Natl Acad Sci 91:5030-5032.

Purves D, White LE, Zheng D, Andrews T, Riddle DR (1994b) Brain size, behavior and the allocation of neural space. In: Individual development over the lifespan: biological and psychosocial perspectives (Magnusson D, ed), in press. Cambridge, UK: Cambridge UP.

Rice FL, Gomez C, Barstow C, Burnet A, Sands P (1985) A comparative analysis of the development of the primary somatosensory cortex: interspecies similarities during barrel and laminar development. J Comp Neurol 236:477-495.

Riddle DR, Richards A, Zsuppan F, Purves D (1992) Growth of the rat somatic sensory cortex and its constituent parts during postnatal developinent. J Neurosci 12:3509-3524.

Riddle D, Gutierrez G, Zheng D, White L, Richards A, Purves D (1993) Differential metabolic and electrical activity in the somatic sensory cortex of juvenile and adult rats. J Neurosci 13:4193-4213.

Springer SP, Deutsch G (1993) Left brain, right brain, 4th ed. New York: Freeman.

Stensaas SS, Eddington DK, Dobelle WH (1974) The topography and variability of the primary visual cortex in man. J Neurosurg 40:747755.

Suga N (1984) Neural mechanisms of complex-sound processing for echolocation. Trends Neurosci 7:20-27. 
Suga N, Jen PH-S (1976) Disproportionate tonotopic representation for processing species specific CF-FM sonar signals in the mustache bat auditory cortex. Science 194:542-544.

Suga N, O'Neill WE (1980) Auditory processing of echoes: representation of acoustic information from the environment in the bat cerebral cortex. In: Animal sonar systems (Busnel RG, Fish JF, eds), pp 589-611. New York: Plenum.

Suga N, Kujisai K, O'Neill WE (1981) Biosonar information is represented in the bat cerebral cortex. In: Neural mechanisms of hearing (Syka J, Aitken L, eds), pp 197-219. New York: Plenum.

Tobet SA, Roca AL, Crandall JE (1993) Cellular organization in rat somatosensory cortex: effects of sex and laterality. Exp Neurol 121: 65-76.

Van der Loos H, Welker E, Dörfl J, Rumo G (1986) Selective breeding for variations in patterns of mystacial vibrissae of mice: bilaterally symmetrical strains derived from ICR stock. J Hered 77:66-82.

Van Fssen DC, Maunsell JHR, Bixby JL (1981) The middle temporal visual area in the macaque: myeloarchitecture, connections, functional properties and topographic organization. J Comp Neurol 199:293326.

Van Essen DC, Newsome WT, Maunsell JHR (1984) The visual field representation in striate cortex of macaque monkey: asymmetries, anisotropics and individual variability. Vision Res 24:427-448.

Wada JA, Clarke R, Hamm A (1975) Cerebral hemispheric asymmetry in humans. Arch Neurol 32:239-246.

Wallace MN (1987) Histochemical demonstration of sensory maps in the rat and mouse cerebral cortex. Brain Res 418:178-182.

Welker C (1971) Microelectrode delineation of fine grain somatotopic organization of SmI ccrcbral ncocortcx in albino rat. Brain Res 26: 259-275.

Welker C (1976) Receptive fields of barrels in the somatosensory neocortex of the rat. J Comp Neurol 166:173-190.

Welker C, Woolsey TA (1974) Structure of layer IV in the somatosensory neocortex of the rat: description and comparison with the mouse. J Comp Neurol 158:437-454.

Welker E, Van der Loos H (1986) Quantitative correlation between barrel-field size and the sensory innervation of the whiskerpad: a comparative study in six strains of mice bred for different patterns of mystacial vibrissae. J Neurosci 6:3355-3373.

Weller WL (1993) SmI cortical barrels in an Australian marsupial, Trichosurus vulpecula (brush-tailed possum): structural organization, patterned distribution, and somatotopic relationships. J Comp Neurol 337:471-492.

White L, Lucas G, Richards A, Purves D (1994) Cerebral asymmetry and handedness. Nature 368:197-198.

Woolsey CN (1958) Organization of somatic sensory and motor areas of the cerebral cortex. In: Biological and biochemical bases of behavior (Harlow HF, Woolsey CN, eds), pp 63-82. Madison, WI: University of Wisconsin.

Woolsey TA (1990) Peripheral alterations and somatosensory development. In: Development of sensory systems in mammals (Coleman JR, ed), pp 461-516. New York: Wiley.

Woolsey TA, Van der Loos H (1970) The structural organization of layer IV in the somatosensory region (SI) of mouse cerebral cortex. Brain Res 17:205-242.

Woolsey TA, Welker C, Schwartz RH (1975) Comparative anatomical studies of the SmI face cortex with special reference to the occurrence of "barrels" in layer IV. J Comp Neurol 164:79-94. 